Please do not remove this page

RMIT

UNIVERSITY

\title{
Thermal analysis of nanofluids in microfluidics using an infrared camera
}

Yi, Pyshar; Kayani, Aminuddin; Chrimes, Adam; Ghorbani, Kamran; Nahavandi, Saeid; Kalantar Zadeh, Kourosh; Khoshmanesh, Khashayar

https://researchrepository.rmit.edu.au/esploro/outputs/9921858391301341/filesAndLinks?institution=61RMIT_INST\&index=null

Yi, P., Kayani, A., Chrimes, A., Ghorbani, K., Nahavandi, S., Kalantar Zadeh, K., \& Khoshmanesh, K. (2012). Thermal analysis of nanofluids in microfluidics using an infrared camera. Lab On a Chip, 12(14), 2520-2525. https://doi.org/10.1039/C2LC40222J

Document Version: Accepted Manuscript

Published Version: https://doi.org/10.1039/C2LC40222J

Repository homepage: https://researchrepository.rmit.edu.au

(c) The Royal Society of Chemistry 2012

Downloaded On 2023/04/26 14:34:34 +1000

Please do not remove this page 
Thank you for downloading this document from the RMIT Research Repository.

The RMIT Research Repository is an open access database showcasing the research outputs of RMIT University researchers.

RMIT Research Repository: http://researchbank.rmit.edu.au/

\section{Citation:}

Yi, P, Kayani, A, Chrimes, A, Ghorbani, K, Nahavandi, S, Kalantar Zadeh, K and Khoshmanesh, K 2012, 'Thermal analysis of nanofluids in microfluidics using an infrared camera', Lab On a Chip, vol. 12, no. 14, pp. 2520-2525.

See this record in the RMIT Research Repository at: http://researchbank.rmit.edu.au/view/rmit:16524

Version: Accepted Manuscript

Copyright Statement: (c) The Royal Society of Chemistry 2012

Link to Published Version:

http://dx.doi.org/10.1039/C2LC40222J

\section{PLEASE DO NOT REMOVE THIS PAGE}




\title{
Thermal analysis of nanofluids in microfluidics using an infrared camera
}

\author{
Pyshar Yi*a ${ }^{a}$, Aminuddin A. Kayani ${ }^{a}$, Adam F. Chrimes ${ }^{a}$, Kamran Ghorbani ${ }^{a}$, Saeid Nahavandi ${ }^{b}$, \\ Kourosh Kalantar-zadeh ${ }^{* a}$, and Khashayar Khoshmanesh ${ }^{* a}$
}

\author{
${ }_{5}$ Received (in $\left.X X X, X X X\right)$ Xth $X X X X X X X X X 20 X X$, Accepted Xth $X X X X X X X X X 20 X X$ \\ DOI: 10.1039/b000000x
}

We present the thermal analysis of liquid containing $\mathrm{Al}_{2} \mathrm{O}_{3}$ nanoparticles in a microfluidic platform using an infrared camera. The small dimensions of the microchannel along with the low flow rates (less than $120 \mu \mathrm{l} / \mathrm{min}$ ) provide very low Reynolds numbers of less than 17.5 , reflecting practical parameters for a 10 microfluidic cooling platform. The heat analysis of nanofluids has never been investigated in such a regime, due to the deficiencies of conventional thermal measurement systems. The infrared camera allows non-contact, three dimensional and high resolution capability for temperature profiling. The system was studied at different $w / w$ concentrations of thermally conductive $\mathrm{Al}_{2} \mathrm{O}_{3}$ nanoparticles and the experiments were in excellent agreement with the computational fluid dynamics (CFD) simulations.

\section{${ }_{15}$ Introduction}

In the early 1980s, Tuckerman and Pease carried out experiments to demonstrate the thermal performance of liquid microchannel heat sinks (MCHSs) ${ }^{1}$. This seminal work shaped a new field of research for cooling of microscale electronic 20 devices; especially in large integrated circuits. The idea of implementing MCHSs was revolutionary for its time. In comparison to the fluid cooling systems of that time, the MCHSs allowed for more efficient heat transfer between the cooling liquid and hot-spots, they required much smaller 25 amount of liquid coolant, liquid could be brought to its cool state much easier, and more surface area was available for an efficient heat transfer ${ }^{2,3}$.

Even though, liquid cooling is fairly prevalent today, it still requires further development due to the intrinsic poor thermal 30 conductivity of conventional fluids. Thus, the attention is now drawing towards the dispersion of solid particles in liquids to enhance the thermal conductivity and consequently the convection coefficient of the flow ${ }^{4-11}$.

The term nanofluids, which introduced by $\mathrm{Choi}^{12}$, was used 35 for describing stable suspensions of nanometer-sized particles with average dimensions of less than $100 \mathrm{~nm}$ in conventional fluids such as water, ethylene glycol or oil. Because nanoparticles such as $\mathrm{Al}_{2} \mathrm{O}_{3}, \mathrm{CuO}, \mathrm{Cu}$ and $\mathrm{TiO}_{2}$ have higher thermal conductivities than the base fluids, even at low

40 concentrations, it is believed that nanofluids offer key potential benefits to $\mathrm{MHCSs}^{13-16}$.

The concept of applying nanofluid coolants in MCHSs has been investigated by different groups ${ }^{13,16-19}$. However, most studies have been performed at high Reynolds numbers ranging ${ }_{45}$ from 100 to $2000^{17,20,21}$, corresponding to either MCHSs with large dimensions or high flow rates. The main technical challenge hindering the operation of such systems is their incompatibility to emerging miniaturised electronic systems, as they need large reservoirs and powerful pumps, which defy the so purpose of miniaturisation and energy efficiency. exploring the thermal properties of microfluidics with nanofluids has been the lack of suitable methods in measuring ${ }_{55}$ temperatures. Thermocouples and thermistors are elements that commonly used to measure the temperature of fluids in microfluidics. They have been widely used by patterning metals incorporated into microchannel ${ }^{22-24}$. However, such elements can only be patterned at limited predetermined ${ }_{60}$ locations of the microchannel. Their measurement is restricted to two dimensional surfaces, and one cannot measure the temperature of three dimensional structures accommodating the microchannel. Moreover, thermocouples require extensive wiring. To solve such problems, temperature-dependent ${ }_{65}$ fluorescent dyes have been used for the detection of fluids' temperatures in microfludics ${ }^{25-27}$. However, this technique might change the thermophysical properties of the fluid, deteriorating the accuracy of measurements.

Nanofluidics investigations have so far been riddled with 70 practical difficulties. Studies on the thermal characteristics of nanofluids has been mostly based on either pure experimental work $^{11,14,28}$ or pure theoretical calculations ${ }^{18,24,29}$, which have been incapable to comprehensively demonstrate the performance of such systems.

75 In our work, we overcome major inaccuracies and problems in exploring microfluidics containing nanofluids. We use a microfluidic system, and integrate it with a microheater and a high resolution infrared (IR) camera. Using the microheater, we are able to accurately control the temperature of the system, 80 and with the IR camera, we can measure the temperatures of any desired location of the microfluidics. Combining these two capabilities, we accurately demonstrate the effect of nanofluids in the thermal performance of the system. We use the suspension of $\mathrm{Al}_{2} \mathrm{O}_{3}$ nanoparticles, which has a high thermal 85 conductivity, at different concentrations to investigate the enhancement of heat exchange in comparison to DI water as the base fluid. The IR camera allows us to observe the thermal characteristics of the system, even at extremely low Reynolds numbers, the values that are associated with true microfluidics 90 and have not been reported before.

Another issue that has been a serious impediment in 
The application of high resolution IR camera enables us to monitor the temperature of desired surfaces at any desired moment. This technique enables us to record the temperature profile of different locations of the microfluidic system, 5 including the 3D structure of the microfluidics block. Advantageously, the measurement is contactless and therefore does not influence the thermal performance of the system. Additionally, the measurement is facile, does not need any specialised training, and enables us to even monitor the 10 dynamic performance of the system.

Our study presents both experimental measurements and numerical simulations to fully understand the response of the system and calculate the heat flux or other variables of the system, which could not be assessed previously.

15

\section{Theory}

Three dimensional numerical simulations were conducted to analyze the variations of velocity, pressure, temperature, and heat loss across the microfluidic system. The highest Reynolds 20 number, $\operatorname{Re}=\rho \bar{U} D / \mu$ ( $\rho$ is fluid density, $\bar{U}$ is the average fluid velocity, $D$ is the hydraulic diameter of the rectangular microchannel, and $\mu$ is the fluid viscosity) obtained at the flow rate of $120 \mu \mathrm{lit} / \mathrm{min}$ is $\sim 17.5$, indicating the laminar characteristics of the flow. The simulation was conducted using

${ }_{25}$ Gambit 2.3 software (Fluent, Lebanon, NH, USA) to create the geometry and mesh generation. Subsequently, the finitevolume based Fluent 6.3 software (Fluent, Lebanon, NH, USA) was used to solve the associated differential equations governing the balance of mass, momentum, and energy within 30 the microfluidic system, as given by Khoshmanesh et $a l^{30}$.

$$
\begin{gathered}
\nabla \cdot \overrightarrow{\mathrm{U}}=0 \\
\rho(\vec{U} \cdot \nabla) \vec{U}=-\nabla P+\mu \nabla^{2} \vec{U} \\
\rho c_{p}(\vec{U} \cdot \nabla) T=k \nabla^{2} T+\dot{Q}
\end{gathered}
$$

where, $\overrightarrow{\mathrm{U}}, P$ and $T$ are the velocity, pressure and temperature of the fluid, $\rho, \mu, c_{p}$ and $k$ are the density, dynamic viscosity, heat capacity and thermal conductivity of the fluid, respectively, 35 and $\dot{Q}$ is the heat source term corresponding to the microheater. The thermophysical properties of nanofluid are obtained as below ${ }^{31}$ :

$$
\begin{gathered}
\rho_{n f}=(1-\phi) \rho_{f}+\phi \rho_{p} \\
\mu_{n f}=\frac{1}{(1-\phi)^{2.5}} \mu_{f} \\
\left(\rho c_{p}\right)_{n f}=(1-\phi)\left(\rho c_{p}\right)_{f}+\phi\left(\rho c_{p}\right)_{p} \\
k_{n f}=\frac{k_{p}+(n-1) k_{f}-(n-1) \phi\left(k_{f}-k_{p}\right)}{k_{p}+(n-1) k_{f}+\phi\left(k_{f}-k_{p}\right)} k_{f} \\
n=\frac{3}{\psi}
\end{gathered}
$$

40 where $f, p$ and $n f$ indices refer to fluid, particle and nanofluid, respectively, $\varnothing$ is the volume fraction of particles in the suspension, $n$ is the shape factor, and $\psi$ is the sphericity of particles, which was taken as 0.5 due to the non-spherical shape of the particles. The thermophysical properties of the base fluid 45 were taken as $\rho_{f}=998 \mathrm{~kg} / \mathrm{m}^{3}, \mu_{f}=0.001$ Pa.s, $c_{p f}=4178 \mathrm{~J} / \mathrm{kg} . \mathrm{K}$ and $k_{f}=0.6 \mathrm{~W} / \mathrm{m} . \mathrm{K}$ while those of $\mathrm{Al}_{2} \mathrm{O}_{3}$ particles were taken as $\rho_{p}=3950 \mathrm{~kg} / \mathrm{m}^{3}, c_{p p}=930 \mathrm{~J} / \mathrm{kg} . \mathrm{K}$ and $k_{p}=40 \mathrm{~W} / \mathrm{m} . \mathrm{K}$.

The Knudsen number, $K n=2 \lambda / d$ ( $\lambda$ is the mean free path length or the average distance between the molecules of DI 50 water and equals to $0.31 \mathrm{~nm}^{32}$, and $d$ is the average diameter of $\mathrm{Al}_{2} \mathrm{O}_{3}$ particles and equals to $30 \mathrm{~nm}$ ) is 0.02 and since it is more than 0.001 , the slip boundary condition is applied at the surfaces of the system. In doing so, the slip velocity was defined as below ${ }^{33}$ :

$$
u_{\text {slip }}=L_{\text {slip }} \lambda \frac{\partial u}{\partial n}
$$

where $L_{\text {slip }}$ is the slip length of PDMS surface taken as $57 \mathrm{~nm}^{34}$ while $\partial u / \partial n$ is the gradient of flow velocity along the axis normal to the surface.

The other boundary conditions consisted of zero pressure at ${ }_{60}$ the inlet and flow rates of 10,40 and $120 \mu \mathrm{L} / \mathrm{min}$ at the outlet (this is because the suspension is sucked out via the outlet). These flow rates associate with the Reynolds numbers in the range of 1.45 to 17.5 . The value of $\dot{Q}$ was obtained by dividing the power supplied to the microheater (by reading the ${ }_{65}$ voltage and current of the DC power supply) by the volume of the microheater. The voltage was changed to maintain the temperature of the microheater centre at $54^{\circ} \mathrm{C}$. The external surfaces of the system exchanged heat with the ambient air via the free convection mechanism assuming the convection 70 coefficient as $10 \mathrm{~W} / \mathrm{m}^{2} . \mathrm{K}$ while the ambient temperature was measured as $25.8^{\circ} \mathrm{C}$. The heat passed through the walls of the glass slide and PDMS via the conduction mechanism with $k_{\text {glass }}=1.05 \mathrm{~W} / \mathrm{m} . \mathrm{K}$ and $k_{P D M S}=0.15 \mathrm{~W} / \mathrm{m} . \mathrm{K}$.

\section{Experimental}

\section{Apparatus}

The schematic of the experimental setup is shown in Fig. 1(A) (refer to Fig. 1S for the real experimental setup). The system consisted of a polydimethylsiloxane (PDMS) block integrated onto a microscopic glass slide, as shown in ${ }_{80}$ Fig. 1(B). The PDMS hosted a microchannel and two reservoirs as the inlet/outlet of the microchannel, as seen in Fig. 1(C). The glass slide accommodated a metallic microheater patterned on its surface as shown in Fig. 1(D). The flow was provided through the microchannel via a syringe ${ }_{85}$ pump (Harvard, PHD 2000 Infusion). The syringe pump was activated in refill mode to supply suction, avoiding the leakage and generation of bubbles within the microchannel. The microheater was energised via a DC power supply (Gw Instek, GPS-X303 series, Taiwan) and was used to heat up the liquid 90 to the desired temperatures before entering the microchannel.

The temperature measurement along the bottom glass surface that covered the microchannel (Fig. 1(C)) was recorded using an IR camera (FLIR Systems, ThermoVision A320, 
Sweden) interfaced with ThermaCAM Researcher software. The microfluidic device was rotated upside down such that the glass substrate was immediately facing the camera, as shown in Fig. 1(A).

\section{A}

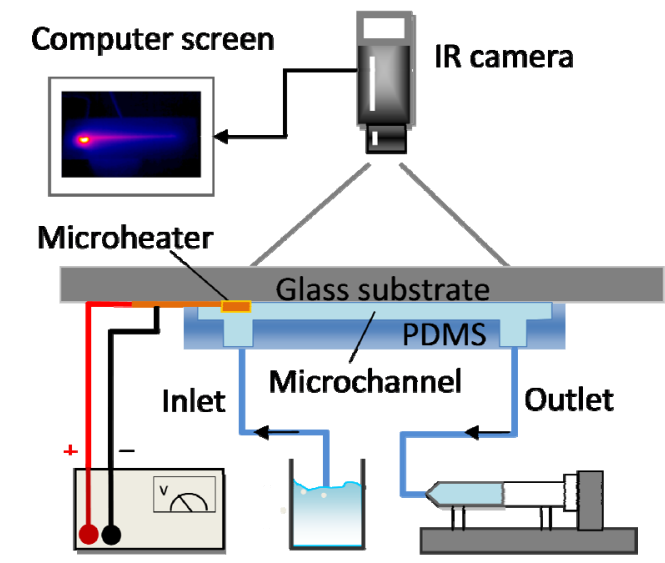

\section{Power supply Nanofluids Syringe pump}

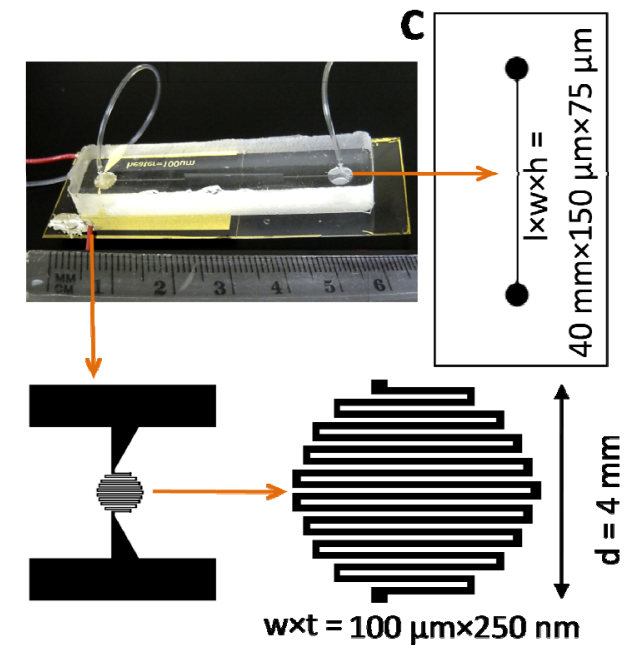

${ }_{35}$ Fig. 1. (A) Schematic of the setup for investigation of nanofluid on heat transfer enhancement consisted of: (B) Microfluidic device, (C) Microchannel design and (D) Microheater pattern.

\section{Nanofluid preparations}

Nanosized, $\mathrm{Al}_{2} \mathrm{O}_{3}$ powders of the diameters of $50 \mathrm{~nm}$ or less were purchased from Sigma-Aldrich, Australia. $\mathrm{Al}_{2} \mathrm{O}_{3}$ was chosen as it has the thermal conductivity of $40 \mathrm{~W} / \mathrm{mK}$ in comparison to DI water of $0.613 \mathrm{~W} / \mathrm{mK}^{35} . \mathrm{Al}_{2} \mathrm{O}_{3}$ powder was 45 suspended in DI water at room temperature to create a final solution of 1 and $2.5 \% w / w$ concentrations. A liquid surfactant (Triton X-305) of $0.2 \% \mathrm{w} / \mathrm{w}$ was added to produce a stable suspension; followed by 20 minutes sonication using an ultrasonic bath (Unisonics, Australia). The dimensions of 50 nanoparticles were confirmed by high resolution scanning electron microscopy (FEI Nova NanoSEM, USA) imaging to be mostly smaller than $50 \mathrm{~nm}$ (Fig. 2). The dynamic light scattering also confirmed that nanoparticles have an average dimension of $\sim 35 \mathrm{~nm}$.

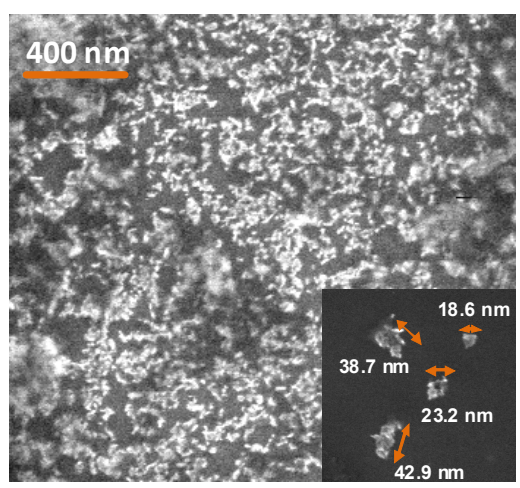

Fig. 2. SEM image of $\mathrm{Al}_{2} \mathrm{O}_{3}$ nanoparticles

\section{Design Details of Microfluidic Chip}

The microchannel was fabricated from PDMS using soft 60 photolithography techniques ${ }^{36,37}$. In doing so, SU8-2050 (Microchem, USA) layer was spin coated on a 3-inch diameter silicon wafer to produce a $75 \mu \mathrm{m}$ thickness layer. The sample was then exposed to UV light source using an MA6 mask aligner for 28 seconds, and developed in SU-8 developer to ${ }_{65}$ recognize the patterns on the master. A $10 \mathrm{~g}$ mixture of PDMS (SYLGARD 184, Dow Corning, USA) base and curing agent was mixed in 10:1 weight ratio, and degassed to remove the trapped air bubbles using a vacuum oven. The PDMS mixture was transferred onto the master and cured in an oven with a 70 temperature of $70^{\circ} \mathrm{C}$ for 20 minutes. The substrate was allowed to cool down for 5 minutes. The PDMS block of $50 \mathrm{~mm} \times$ $10 \mathrm{~mm} \times 5 \mathrm{~mm}($ length $\times$ width $\times$ height $)$ was carefully peeled from the master. The microchannel dimensions were set to $150 \mu \mathrm{m} \times 75 \mu \mathrm{m} \times 40 \mathrm{~mm}$ (width $\times$ height $\times$ length). The 75 channel's height of $75 \mu \mathrm{m}$ was chosen to allow a free flow of naonoparticles with sizes less than $50 \mathrm{~nm}$ and prevent clogging.

The PDMS block was integrated onto a glass slide (Menzel-Glaser, USA) of $60 \mathrm{~mm} \times 20 \mathrm{~mm} \times 100 \mu \mathrm{m}$ (length $\times$ width $\times$ height). The glass thickness of $100 \mu \mathrm{m}$ was chosen to 80 facilitate the exchange of heat between the liquid and the environment, as well as allowing the most efficient observation using the IR camera. The microheater was patterned onto the glass substrate using photolithography. In doing so, thin layers of $\mathrm{Au} / \mathrm{Cr}(150 / 100 \mathrm{~nm})$ were deposited on the glass surface 85 using electron beam evaporation process. Next, the substrate was spun coated with AZ1512 photo-resist using a spinner (Karl Suss RC8). This substrate was baked in an oven at $90{ }^{\circ} \mathrm{C}$ for 20 minutes, before exposure to UV light through a PDF mask. Subsequently, the exposed substrate was developed in ${ }_{90}$ AZ400K developer and a gold etchant (niro-hydrochloric acid, $1: 4 v / v$ ratios) was applied to etch the unwanted gold. The substrate was rinsed and cleaned using acetone, methanol and DI water. A chromium etchant was then used to remove the excess chromium.

95 The substrate was again cleaned with acetone, methanol, DI water and air dry. The fabrication process was conducted in 
a class 1000 cleanroom. Microtubes with an internal diameter of $\sim 400 \mu \mathrm{m}$ were placed into the holes punched of the PDMS. These tubes allowed the interfacing of syringe pumps and samples with the microchannel.

\section{Measurements}

First, we investigated the thermal performance of our microfluidic system using DI water as the working fluid at a flow rate of $40 \mu \mathrm{lit} / \mathrm{min}$. We placed the IR camera at a distance 10 of $0.3 \mathrm{~m}$ from any surface of the microfluidic system which we were interested to measure its temperature. The voltage of DC power supply was varied to provide a constant temperature of $54{ }^{\circ} \mathrm{C}$ at the middle of the inlet reservoir when seen from the glass side. The temperatures were recorded in 90 second frames 15 using the IR camera and the images were extracted from the last frame. Examples of these measurements are shown in Fig. 3(A-C). As clearly seen in the images, the IR camera enables us to observe how the heat is dissipated within the PDMS block, the glass slide, and more importantly throughout 20 the microchannel. We also compared the measured temperature with results of CFD simulations, as shown in Fig. 3(D-F). The colours of the temperature bar are selected to match with the IR camera settings. However, the exact comparison between the experimental and numerical results is given later.

25 Next, we moved on to characterise the thermal performance of our microfluidic system at different flow rates and concentrations of $\mathrm{Al}_{2} \mathrm{O}_{3}$ nanoparticles.
Figs. 4(A-C) show the temperature profiles across the glass slide (the bottom view) after applying only DI water through 30 the system at different flow rates of 10,40 and $120 \mu \mathrm{lit} / \mathrm{min}$. These figures clearly show the extension of golden $\left(50-40^{\circ} \mathrm{C}\right)$ and pink $\left(40-30^{\circ} \mathrm{C}\right)$ regions throughout the glass surface by increasing the flow rate. Obviously at higher flow rates convection becomes the dominant mode of heat transfer along 35 the microchannel, as the liquid does not have enough time to lose its internal heat to the environment via the channel surfaces.

Figs. 4(D-F) show the temperature profiles across the glass slide (the bottom view) after applying DI water and water 40 mixed with $\mathrm{Al}_{2} \mathrm{O}_{3}$ concentrations of $1 \%$ and $2.5 \% \mathrm{w} / \mathrm{w}$ at a constant rate of $40 \mu \mathrm{lit} / \mathrm{min}$. By careful examination of the temperature contours one can see their changes due to incorporation of nanoparticles. As can be seen, the increased thermal conductivity of liquid with $2.5 \% w / w \mathrm{Al}_{2} \mathrm{O}_{3}$ increases

45 the heat conduction along the microchannel, reducing the temperature gradient along the length.

To quantify the thermal impact of the nanoparticles, we investigated the variations of temperature along the microchannel centreline. In doing so, we defined 38 points 50 along this line and read their temperatures using the images obtained from the IR camera. Fig. 5(A) shows the variations of temperature along this centreline of the microchannel at different flow rates of 10,40 and $120 \mu \mathrm{lit} / \mathrm{min}$ and different $\mathrm{Al}_{2} \mathrm{O}_{3}$ concentrations of $0 \%, 1 \%$ and $2.5 \%$ suspended in DI 55 water.
A

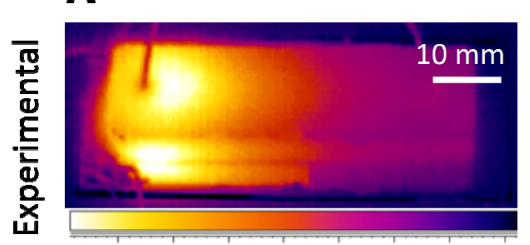

$34^{\circ} \mathrm{C}$

D

65

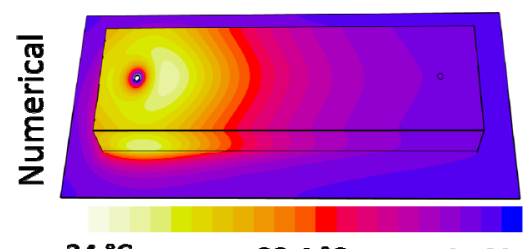

$34{ }^{\circ} \mathrm{C}$
B

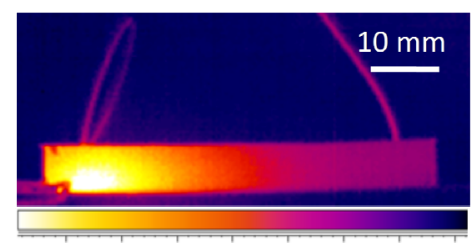

$29.5^{\circ} \mathrm{C}$

E

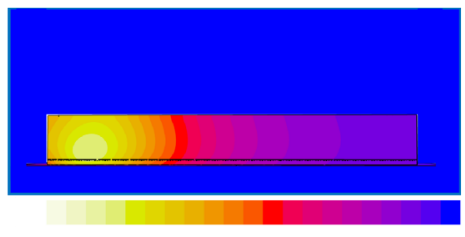

C

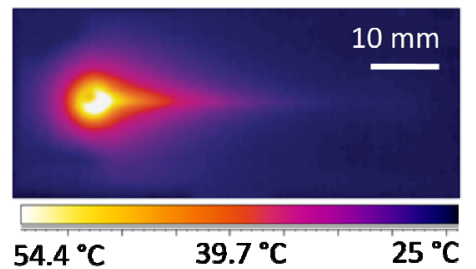

$\mathbf{F}$

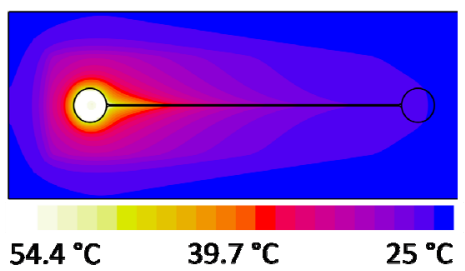

Fig. 3. Temperature distribution across the external surfaces of the microfluidic system with DI water at a flow rate of $40 \mu$ lit/min. Measured temperatures using infrared camera: (A) 3D view, (B) side view and (C) bottom view, Calculated temperatures using CFD simulations: (D) 3D view, (E) side view and (F) bottom view. 
DI water

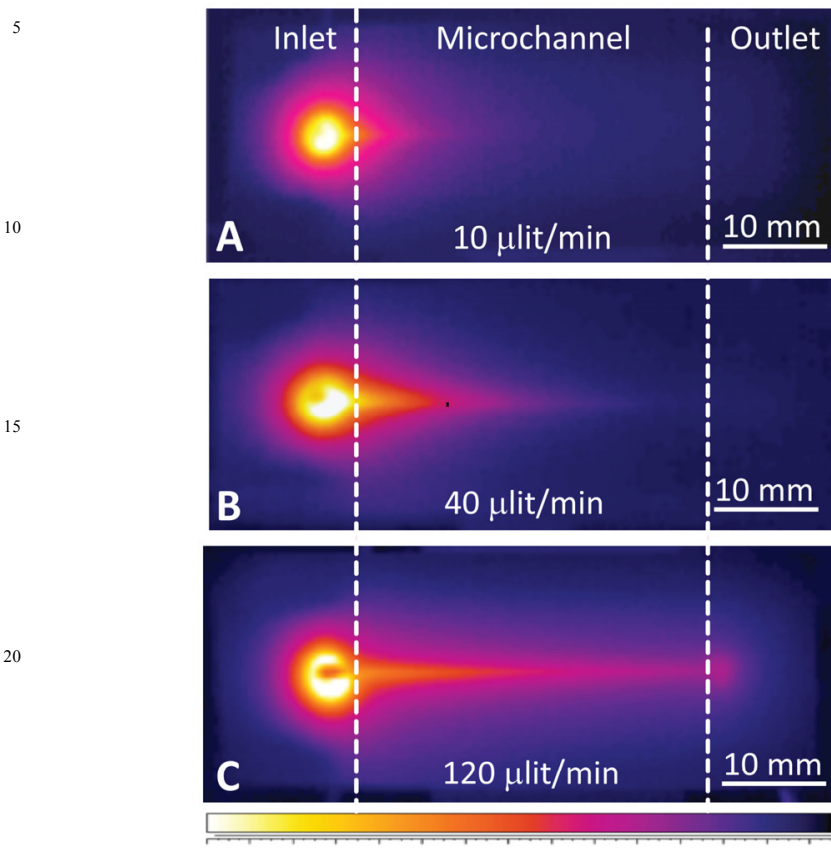

Fig. 4. Temperature distribution across the bottom surface of glass slide: (A-C) DI water as the working fluid at different flow rates of 10,40 and $120 \mu \mathrm{lit} / \mathrm{min}$, (D-F) DI water with different $\mathrm{Al}_{2} \mathrm{O}_{3}$ concentrations of $0 \%, 1 \%$ and $2.5 \%$ w/w at a constant flow rate of $40 \mu \mathrm{lit} / \mathrm{min}$

\section{${ }_{30}$ Results and Discussions}

Fig. 5(A) shows the outcomes of measurements only. This figure demonstrates that the temperature drop, along the microchannel centreline, decreases significantly by increasing the flow rate of DI water and liquid suspensions incorporating $35 \mathrm{Al}_{2} \mathrm{O}_{3}$ nanoparticles, indicating the enhancement of convection within the microchannel at higher flow rates. For example, for the case of DI water, while a temperature drop of $28^{\circ} \mathrm{C}$ was observed along the centreline at $10 \mu \mathrm{lit} / \mathrm{min}$, it reduced to $25^{\circ} \mathrm{C}$ at $40 \mu \mathrm{lit} / \mathrm{min}$ and further reduced to $21^{\circ} \mathrm{C}$ at $120 \mu \mathrm{lit} / \mathrm{min}$. 40 Similar trends can be seen for other concentrations of $\mathrm{Al}_{2} \mathrm{O}_{3}$. Fig. 5(A) also shows that the temperature drop along the microchannel decreases by increasing the concentration of $\mathrm{Al}_{2} \mathrm{O}_{3}$, indicating the superior thermal conductivities of nanofluids. For example at $10 \mu \mathrm{lit} / \mathrm{min}$, while a temperature 45 drop of $28.2^{\circ} \mathrm{C}$ was observed along the centreline for DI water, it reduced to $27.6^{\circ} \mathrm{C}$ for the $1 \% \mathrm{Al}_{2} \mathrm{O}_{3}$ suspension and further reduced to $27.4^{\circ} \mathrm{C}$ for the $2.5 \% \quad \mathrm{Al}_{2} \mathrm{O}_{3}$ suspension. Interestingly, the effectiveness of nanofluids was more tangible at higher flow rates. For example at $120 \mu \mathrm{lit} / \mathrm{min}$, while a 50 temperature drop of $22.7^{\circ} \mathrm{C}$ was observed along the centreline for DI water, it reduced to $21.6^{\circ} \mathrm{C}$ for the $1 \% \mathrm{Al}_{2} \mathrm{O}_{3}$ suspension and further reduced to $19.5^{\circ} \mathrm{C}$ for the $2.5 \% \mathrm{Al}_{2} \mathrm{O}_{3}$ suspension.

Figs. 5(B-C) compare the variations of experimental and simulated temperatures along the centreline. Results show an ${ }_{55}$ excellent agreement between the experimental and numerical
Flow rate of $40 \mu$ lit/min
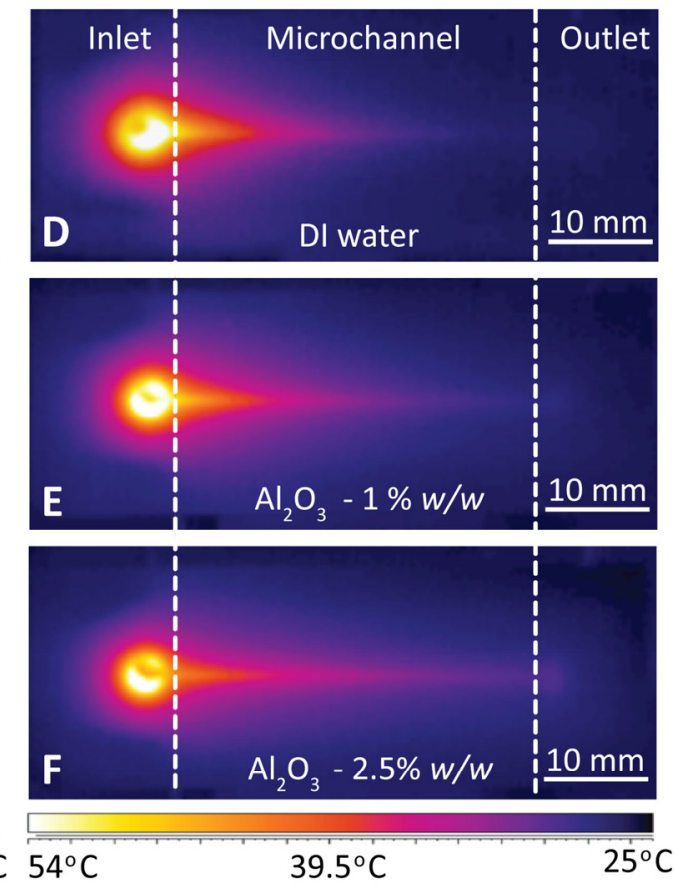

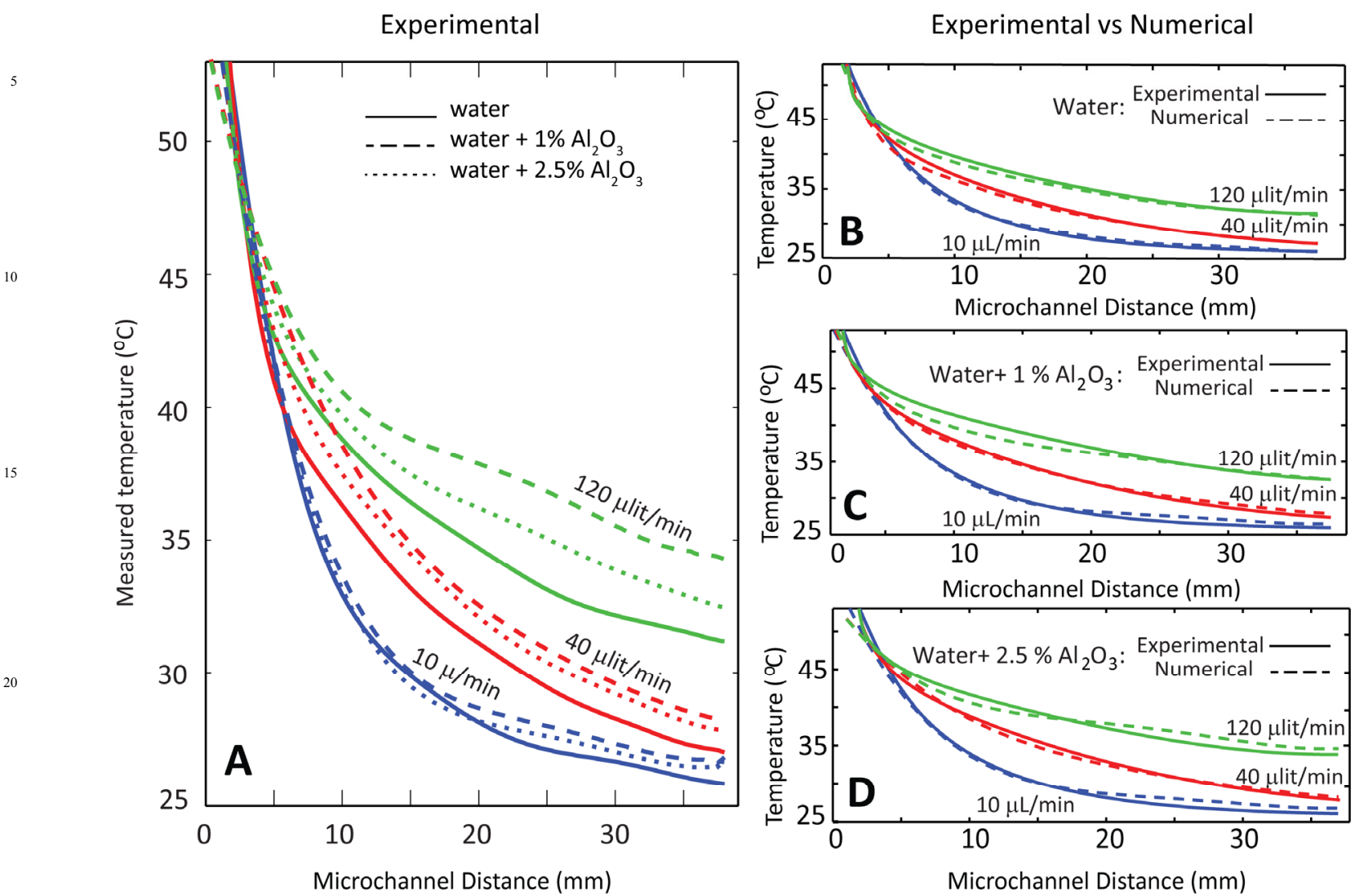

${ }_{25}$ Fig. 5. Variation of temperature at the bottom surface of the microfluidic system along the centreline: (A) Experimental temperatures at the flow rates of 10, 40 and $120 \mu \mathrm{lit} / \mathrm{min}$, and different $w / w \mathrm{Al}_{2} \mathrm{O}_{3}$ concentrations of $0 \%, 1 \%$ and $2.5 \%$. (B-D) Experimental versus numerical temperatures at 10, 40 and $120 \mu \mathrm{lit} / \mathrm{min}$ for (B) DI water, (C) water plus $1 \% w / w \mathrm{Al}_{2} \mathrm{O}_{3}$ and (D) water plus $2.5 \% w / w \mathrm{Al}_{2} \mathrm{O}_{3}$.

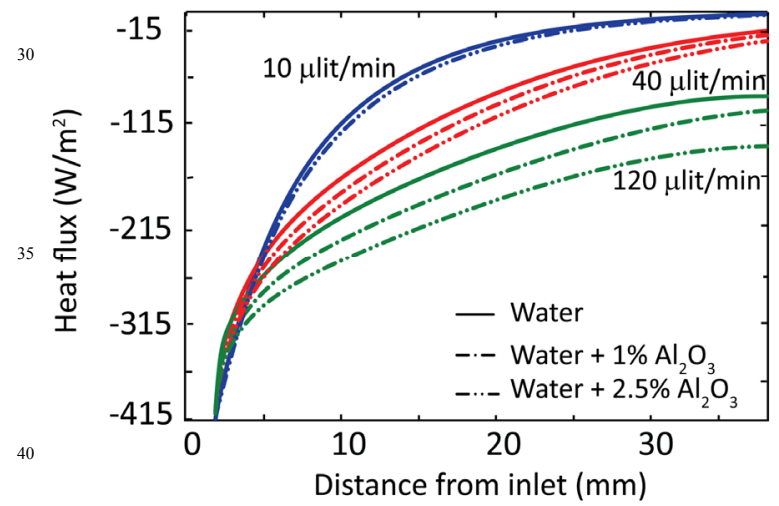

Fig. 6. Heat flux profile along the centreline at different flow rates and various concentrations of $\mathrm{Al}_{2} \mathrm{O}_{3}$ nanoparticles.

\section{Conclusion}

The work is a comprehensive analysis of heat transfer in a 50 true micofluidic system with and without suspended $\mathrm{Al}_{2} \mathrm{O}_{3}$ nanoparticles. According to our observations, at low flow rate of $10 \mu \mathrm{lit} / \mathrm{min}$, associated with the Reynolds number of 1.45 , no significant difference was observed between the conventional fluid and nanofluids, as also confirmed by the 55 numerical simulations. In contrast, at higher flow rates of $120 \mu \mathrm{lit} / \mathrm{min}$, associated with the Reynolds number of 17.5 , the exchange of heat for the liquid with nanoparticles was much enhanced. All the observations were based on the incorporation of an IR camera for measuring the temperature profiles, which 60 was non-contact without affecting the thermal properties of the platform. Further improvement of the system is needed to account for a number of factors such as the investigation of different sizes and types of nanoparticles as well as the modification of the microchannel design in order to obtain ${ }_{65}$ higher heat transfer efficiencies.

As nanoparticles are becoming more readily accessible, their application in microfluidics is becoming increasingly attractive. Future Very Large Scale Integration (VLSI) of electronic elements requires exceedingly more components, and 70 consequently more efficient cooling systems. Nanofluids will certainly play an important role in providing solutions for the 
cooling issues of such complex systems.

\section{Notes and references}

${ }^{a}$ RMIT University, School of Electrical and Computer

Engineering, Melbourne, Victoria, Australia.

5 Tel: (03) 99253254.

E-mail:pyshar.yi@gmail.com,

kourosh.kalantar@rmit.edu.au and

khashayar.khoshmanesh@rmit.edu.au

${ }^{b}$ Centre for Intelligent Systems Research, Deakin University,

10 Victoria, Australia.

† Electronic Supplementary Information (ESI) available.

[Experimental setup] see DOI: 10.1039/b000000x/

15 .1. D. B. Tuckerman and R. F. W. Pease, Electron Device Letters, 1981, 2, 126-129.

2. D. Erickson, D. Sinton and D. Q. Li, Lab on a Chip, 2003, 3, 141149.

3. J. Atencia and D. J. Beebe, Nature, 2005, 437, 648-655.

20 4. M. P. Beck, T. F. Sun and A. S. Teja, Fluid Phase Equilibria, 2007, 260, 275-278.

5. H. Q. Xie, J. C. Wang, T. G. Xi, Y. Liu, F. Ai and Q. R. Wu, Journal of Applied Physics, 2002, 91, 4568-4572.

6. W. Yu and S. U. S. Choi, Journal of Nanoparticle Research, 2003,

$$
25 \quad \mathbf{5}, 167-171 \text {. }
$$

7. S. M. S. Murshed, K. C. Leong and C. Yang, International Journal of Thermal Sciences, 2005, 44, 367-373.

8. S. Movahed and D. Li, Electrophoresis, 2011, 32, 1259-1267.

9. S. Ozerinc, S. Kakac and A. G. Yazicioglu, Microfluidics and Nanofluidics, 2009, 8, 145-170.

10. C. L. Altan and S. Bucak, Nanotechnology, 2011, 22, 285713

11. C. H. Li and G. P. Peterson, Journal of Applied Physics, 2006, 99.

12. S. U. S. Choi, Developments and Applications of Non-Newtonian Flows, 1995, 231, ASME, 99-105.

35 13. H. A. Mohammed, P. Gunnasegaran and N. H. Shuaib, International Communications in Heat and Mass Transfer, 2011, 38, 194-201.

14. R. Chein and J. Chuang, International Journal of Thermal Sciences, 2007, 46, 57-66.

40 15. R. Y. Chein and G. M. Huang, Applied Thermal Engineering, 2005, 25, 3104-3114

16. T. H. Tsai and R. Chein, International Journal of Heat and Fluid Flow, 2007, 28, 1013-1026.

17. H. A. Mohammed, P. Gunnasegaran and N. H. Shuaib, 45 International Communications in Heat and Mass Transfer, 2011, 38, 767-773.
18. E. Farsad, S. P. Abbasi, M. S. Zabihi and J. Sabbaghzadeh, Heat and Mass Transfer, 2011, 47, 479-490.

19. H. A. Mohammed, P. Gunnasegaran and N. H. Shuaib, International Communications in Heat and Mass Transfer, 2010, 37, 1496-1503.

20. X. Wu, H. Wu and a. P. Cheng, Journal of Micromechanics Micorengineering, 2009, 19.

21. D. S. Wen and Y. L. Ding, Microfluidics and Nanofluidics, 2005,

$$
55 \quad \text { 1, 183-189. }
$$

22. U. Seger-Sauli, M. Panayiotou, S. Schnydrig, M. Jordan and P. Renaud, Electrophoresis, 2005, 26, 2239-2246.

23. P. B. Allen, I. Rodriguez, C. L. Kuyper, R. M. Lorenz, P. SpicarMihalic, J. S. Kuo and D. T. Chiu, Analytical Chemistry,

$60-2003, \mathbf{7 5}, 1578-1583$

24. Q. Z. Xue, Physics Letters A, 2003, 307, 313-317.

25. D. Ross, M. Gaitan and a. L. E. Locascio, Analytical Chemistry, 2001, 73, 4117-4123.

26. R. Fu, B. Xu and D. Li, International Journal of Thermal Sciences, $65 \quad 2006, \mathbf{4 5}, 841-847$

27. A. Gunther, S. A. Khan, M. Thalmann, F. Trachsel and a. K. F. Jensen, Lab on a Chip, 2004.

28. S. Shaikh, K. Lafdi and R. Ponnappan, Journal of Applied Physics, 2007.

70 29. P. Bhattacharya, A. Samanta and S. Chakraborty, Heat and Mass Transfer, 2009, 45, 1323-1333.

30. K. Khoshmanesh, J. Akagi, S. Nahavandi, J. Skommer, S. Baratchi, J. M. Cooper, K. Kalantar-zadeh, D. E. Williams and D. Wlodkowic, Analytical Chemistry, 2011, 83, 21332144.

75

31. A. Ijam and R. Saidur, Applied Thermal Engineering, 2012, 32, 76-82.

32. S. J. Perkins, European Journal of Biochemistry, 1986, 157, 169180.

80 33. A. Moshfegh, M. Shams, G. Ahmadi and R. Ebrahimi, Colloids and Surfaces A: Physicochemical and Engineering Aspects, 2009, 345, 112-120

34. P. Huang, J. S. Guasto and K. S. Breuer, Journal of Fluid Mechanics, 2006, 566, 447-464.

85 35. S. Kakaç and A. Pramuanjaroenkij, International Journal of Heat and Mass Transfer, 2009, 52, 3187-3196.

36. K. Kalantar-zadeh, K. Khoshmanesh, A. A. Kayani, S. Nahavandi and A. Mitchell, Applied Physics Letters, 2010, 96.

37. A. F. Chrimes, A. A. Kayani, K. Khoshmanesh, P. R. Stoddart, P. Mulvaney, A. Mitchell and K. Kalantar-zadeh, Lab on a Chip, 2011, 11, 921-928. 